\title{
PROFIL KOMPETENSI GURU DALAM MANFAATAN TEKNOLOGI INFORMASI DAN KOMUNIKASI (TIK) SEBAGAI MEDIA PEMBELAJARAN DI KABUPATEN SORONG
}

\author{
Anang Triyoso 1 \\ Doni Sudibyo ${ }^{1}$ \\ ${ }^{1}$ STKIP Muhammadiyah Sorong \\ e-mail:atriyoso@yahoo.com
}

\begin{abstract}
Abstrak: Penelitian ini bertujuan mencari informasi tentang sejauhmana kompetensi guru dalam memanfaatkan teknologi informasi dan komunikasi sebagai media dalam proses pembelajaran dan faktor-faktor yang mendukung dan menghambat pemanfaatannya. Sampel di dalam penelitian ini adalah para guru dan kepala sekolah tingkat dasar dan menengah Muhammadiyah yang ada di kabupaten Sorong sebanyak 5 guru dan 5 Kepala Sekolah. Teknik pengumpulan data dalam penelitian ini adalah menggunakan kuisioner yang diisi oleh responden, Sedangkan metode analisis datanya adalah metode deskriptif kuantitatif, dimana penyajian data ditampilkan dalam bentuk table dan grafik. Hasilnya menunjukkan bahwa hanya 54\% guru yang kompeten untuk memanfaatkan teknologi informasi dan komunikasi dalam pembelajaran disekolahnya dan hanya mencapai 58\% kepala sekolah dalam kebijakannya berhasil mendorong pemanfaatan teknologi informasi dan komunikasi di sekolahnyaBerdasarkan hasil ini, maka perlu dilakukan upaya untuk meningkatkan kompetensi guru dalam pemanfaatan teknologi informasi dan komunikasi sebagai media pembelajaran.
\end{abstract}

Kata Kunci: Kompetensi Guru, Teknologi Informasi Dan Komunikasi, Media Pembelajaran

\begin{abstract}
This research was aimed to find information about the extent of teachers competence in using information and communication technology as a medium in the learning process and supporting factors, inhibiting the use of it. The samples in this research were the teachers and headmasters of Muhammadiyah elementary school and secondary schools in Sorong regency, with 5 teachers and 5 headmasters. Data collection techniques in this research is using a questionnaires with completed by the respondents, while the method of data analysis is descriptive quantitative method, where the presentation of the data shown in tables and graphs. The results showed that only 54\% of teachers who are competent to use information and communication technology in learning in their school and only reached $58 \%$ of headmasters in successful policy to encourage the use of information and communication technology in schools. Based on this results that needs to make efforts to improve the competence of teachers in using of information and communication technology as a learning media.
\end{abstract}

Keywords: CompetenceOfTeachers, Information And Communication Technology, Learning Media

\section{PENDAHULUAN}

Globalisasi sebagai dampak dari revolusi teknologi informasi dan komunikasi (TIK) mengakibatkan perubahan besar dalam berbagai aspek kehidupan. Meluasnya perkembangan infrastruktur informasi global telah mengubah pola dan cara kegiatan bisnis, industri, perdagangan, dan pemerintah. Perkembangan ekonomi berbasis ilmu pengetahuan dan informasi telah menjadi paradigma global yang dominan. Kemampuan untuk terlibat secara efektif dalam revolusi jaringan informasi akan menentukan masa depan kesejahteraan bangsa.

Perkembangan teknologi informasi dan komunikasi yang begitu pesat digunakan dalam berbagai disiplin ilmu, termasuk di dunia pendidikan. Perkembangan pemanfaatan teknologi informasi dan komunikasi dalam dunia pendidikan saat ini sudah tidak bisa ditawar lagi karena telah menyatu dengan perkembangan setiap aktivitas kehidupan, tidak terkecuali dalam dunia pendidikan. Demikian halnya guru sebagai tenaga profesional, harus mampu mengimbangi laju perubahan tersebut. Sikap yang harus direfleksikan oleh guru di antaranya melalui apresiasi, inovasi, dan kreasi untuk memanfaatkan TIK seperti yang dinyatakan dalam Peraturan Menteri Pendidikan Nasional (Permendiknas) Nomor 16 Tahun 2007 tentang Standar Kualifikasi Akademik dan kompetensi Guru.

Permendiknas nomor 16 tahun 2007 tentang standar kualifikasi akademik dan kompetensi guru yaitu standar kompetensi guru mata pelajaran SD/MI, SMP/MTs, SMA/MA, dan SMK/MAK pada kompetensi pedagogik yaitu agar memanfaatkan teknologi informasi dan komunikasi untuk kepentingan pembelajaran yang diampu dan pada kompetensi profesional yaitu agar memanfaatkan teknologi informasi dan komunikasi untuk pengembangan diri. Pemenuhan kualifikasi dan kompetensi guru tersebut kini terasa sangat kompleks seiring dengan pesatnya 
kemajuan teknologi informasi dan komunikasi (TIK) atau disebut pula telematika, serta meluasnya perkembangan infrastruktur informasi global.

Berbagai keadaan menunjukkan bahwa masih banyak satuan pendidikan dan guru yang belum ma mp u mendayagunakan potensi TIK yang dimiliki secara baik, dan oleh karena itu sekolah dan guru terancam kesenjangan digital (digital divide). Kesenjangan sarana dan prasarana TIK antara kota dan pedesaan, kawasan barat dan timur Indonesia, juga memperlebar jurang perbedaan penyediaan TIK. Berdasarkan hasil monitoring, supervisi, dan evaluasi keterlaksanaan RSKM/KT SP Direktorat Pembinaan SMA (2010), ditemukan bahwa pemanfaatan TIK (baik hard ware maupun software) oleh guru di satuan pendidikan masih amat terbatas. TIK lebih banyak dimanfaatkan terbatas pada fungsi administratif. Pemanfaatannya sebagai media atau alat bantu pembelajaran dan penilaian masih belum tereksplorasi secara mendalam, apalagi pemanfaatan berbagai fasilitas dan aplikasi yang ada. Sejalan dengan hasil temuan tersebut, upaya pembangunan bidang pendidikan banyak menghadapi berbagai tantangan.Salah satu tantangan yang cukup menarik adalah yang berkenaan dengan peningkatan mutu pendidikan, yang ditunjukkan dengan masih rendahnya kualitas guru itu sendiri dalam pemanfaatan TIK dalam pembelajaran.

Di tangan gurulah hasil pembelajaran yang merupakan salah satu indikator mutu pendidikan lebih banyak ditentukan, yakni pembelajaran yang baik sekaligus bernilai sebagai pemberdayaan kemampuan (ability) dan kesanggupan (capability) peserta didik. Tanpa guru yang dapat dijadikan andalannya, mustahil suatu sistem pendidikan dapat mencapai hasil sebagaimana diharapkan. Maka prasyarat utama yang harus dipenuhi bagi berlangsungnya proses belajar mengajar yang menjamin optimalisasi hasil pembelajaran ialah tersedianya guru dengan kualifikasi dan kompetensi yang mampu memenuhi tuntutan tugasnya. Hal ini menunjukkan bahwa di sinilah letak kendala pedagogis dan profesionalitas yang dimiliki para guru untuk dapat segera diperbaiki.

Kendala pedagogis dan profesionalitas yang dimiliki oleh para guru tersebut di atas, dialami oleh para guru yang berada di Kabupaten Sorong.Kabupaten Sorong merupakan salah satu kabupaten di Provinsi Papua Barat yang terletak di kepala burung pulau Papua.Sampai dengan tahun 2008, Kabupaten Sorong memiliki satuan pendidikan baik negeri maupun swasta yang terdiri dari 32 TK, 123 SD/MI, 30 SLTP dan 19 SLTA sederajat.(Sorong dalam Angka, 2009). Termasuk pula didalamnya sekolah swasta khususnya dibawah naungan yayasan Muhammadiyah yang memiliki 17 TK, 4 SD/MI, 6 SLTP dan 4 SLTA.

Berdasarkan uraian di atas, maka dilakukan penelitian ini dengan tujuan untuk mengetahui bagaimana profil kompetensi guru dalam pemanfaatan teknologi informasi dan komunikasi demi kepentingan pembelajaran. Hasil dari peneletian ini diharapkan dapat digunakan sebagai informasi untuk memperbaiki kompetensi guru khusus padakopempetensi pedagogik dan pengembangan diri pada kompetensi professional guru dalam menggunakan TIK sebagai media pembelajaran.

\section{METODE PENELITIAN}

Metode dalam penelitian ini menggunakan metode deskriptif kuantitatif. Penelitian deskriptif bertujuan untuk membuat gambaran secara faktual dan akurat mengenai fenomena dan sifat-sifat populasi di daerah tertentu. ( Partino 2007:59).

Sampel yang diambil dalam penelitian ini terdiri dari beberapa sumber yakniguru dan kepala sekolah.Guru sebagaisampel data diambil dari 5 Sekolah Dasar dan Menengah Muhammadiyah Kabupaten Sorong secara representatif dengan menggunakan teknik pengambilan data purposive sampling tiap sekolahnya. SedangkanKepala Sekolah yang menjadi responden adalah sebanyak 5 orang.

Metode pengumpulan data yang digunakan dalam penelitian ini menggunakan kuesioner, yaitu teknik pengumpulan data untuk menggali kompetensi melalui penyebaran instrumen kepada para responden untuk diisi atau dijawab. Instrumen juga diberikan kepada kepala sekolah. Alasan mengapa kepala sekolah juga dimasukkan ke dalam responden adalah karena kebijakan yang diambil oleh kepala sekolah akan mempengaruhi proses pembelajaran guru di kelas, terutama kebijakan yang mendukung kearah implementasi teknologi informasi dalam pembelajaran. Instrumen ini merupakan instrumen penunjang, agar data dari kompetensi guru dapat menjadi lebih mendukung.

Data hasil penyebaran kuisioner yang diperoleh dianalisis secara kuantitatif untuk melihat persentase tingkat kompetensinya, selanjutnya data hasil perhitungan persentase dianalisis secara deskriptif untuk melihat sejauhmana pemanfaatan TIK sebagai media pembelajaran di Kabupaten Sorong.

\section{HASIL DAN PEMBAHASAN}

Pada bagian ini disajikan deskripsi data hasil dari sebaran kuisioner yang diisi/dijawab oleh responden guru dalam memanfaatkan TIK dalam pembelajaran. 
Tabel 1: Presentasi Kemampuan Guru dalam mem an faa tha n TIK dalam pembelajaran

\begin{tabular}{|c|c|c|c|c|c|c|c|c|}
\hline \multirow{2}{*}{$\begin{array}{c}\text { Butir } \\
\text { Pertanyaan }\end{array}$} & \multicolumn{5}{|c|}{ Nama Guru } & \multirow{2}{*}{ Jumlah } & \multirow{2}{*}{$\begin{array}{c}\text { Rata- } \\
\text { rata }\end{array}$} & \multirow{2}{*}{$\begin{array}{l}\text { Persen- } \\
\text { tase }\end{array}$} \\
\hline & $A$ & B. & C. & D & E & & & \\
\hline 1 & 0 & 1 & 0 & 1 & 1 & 3 & 0.6 & $60 \%$ \\
\hline 2 & 0 & 1 & 0 & 0 & 1 & 2 & 0.4 & $40 \%$ \\
\hline 3 & 1 & 1 & 0 & 0 & 1 & 3 & 0.6 & $60 \%$ \\
\hline 4 & 1 & 1 & 1 & 1 & 1 & 5 & 1 & $100 \%$ \\
\hline 5 & 0 & 1 & 1 & 1 & 0 & 3 & 0.6 & $60 \%$ \\
\hline 6 & 0 & 1 & 1 & 1 & 1 & 4 & 0.8 & $80 \%$ \\
\hline 7 & 0 & 0 & 1 & 1 & 1 & 3 & 0.6 & $60 \%$ \\
\hline 8 & 0 & 1 & 1 & 1 & 1 & 4 & 0.8 & $80 \%$ \\
\hline 9 & 1 & 1 & 1 & 1 & 1 & 5 & 1 & $100 \%$ \\
\hline 10 & 0 & 1 & 1 & 1 & 1 & 4 & 0.8 & $80 \%$ \\
\hline 11 & 0 & 1 & 1 & 1 & 1 & 4 & 0.8 & $80 \%$ \\
\hline 12 & 0 & 1 & 1 & 0 & 0 & 2 & 0.4 & $40 \%$ \\
\hline 13 & 0 & 1 & 0 & 0 & 0 & 1 & 0.2 & $20 \%$ \\
\hline 14 & 0 & 1 & 0 & 0 & 0 & 1 & 0.2 & $20 \%$ \\
\hline 15 & 1 & 0 & 0 & 0 & 1 & 2 & 0.4 & $40 \%$ \\
\hline 16 & 0 & 0 & 0 & 0 & 1 & 1 & 0.2 & $20 \%$ \\
\hline 17 & 1 & 1 & 1 & 1 & 1 & 5 & 1 & $100 \%$ \\
\hline 18 & 1 & 0 & 1 & 0 & 1 & 3 & 0.6 & $60 \%$ \\
\hline 19 & 0 & 0 & 0 & 0 & 0 & 0 & 0 & $0 \%$ \\
\hline 20 & 0 & 0 & 0 & 0 & 0 & 0 & 0 & $0 \%$ \\
\hline 21 & 1 & 0 & 1 & 0 & 1 & 3 & 0.6 & $60 \%$ \\
\hline 22 & 0 & 1 & 0 & 0 & 0 & 1 & 0.2 & $20 \%$ \\
\hline 23 & 0 & 0 & 0 & 0 & 0 & 0 & 0 & $0 \%$ \\
\hline \multicolumn{8}{|c|}{ Total } & $54 \%$ \\
\hline
\end{tabular}

Sumber : hasil penelitian, 2012

Untuk lebih jelas dapat kita lihat pada gambar grafik histogram berikut ini:

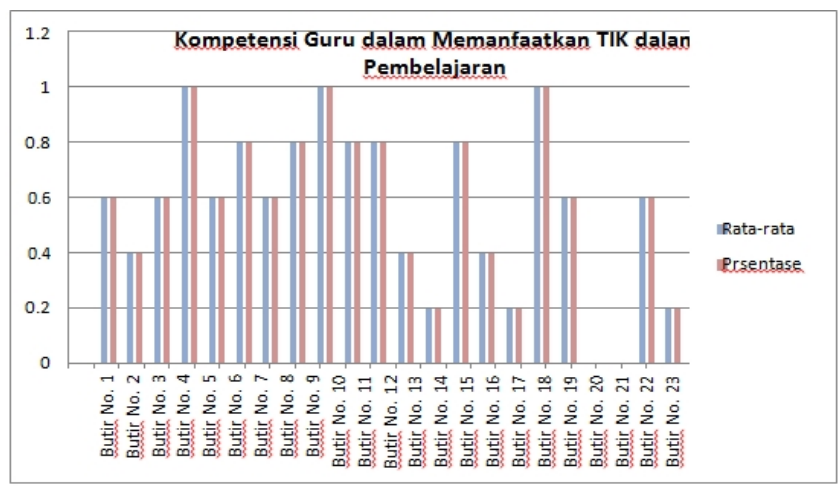

Gambar 1. Kompetensi Guru dalam Memanfaatkan TIK dalam Pembelajaran

Berdasarkan data pada Tabel 1 diperoleh data sebagai berikut.Sebanyak $60 \%$ guru ternyata memiliki akses ke komputer yang dapat diandalkan di rumah dan/atau di sekolah (butir 1), namunhanya $40 \%$ guru memiliki akses ke internet di rumah atau di sekolah (butir 2). Selanjutnya sebanyak $60 \%$ guru mengaku mudah mendapatkan warnet yang dapat di sekitar lingkungan mereka (butir 3). Selanjutnya, meskipun sebanyak 100\% guru mengaku lancar menggunakan program Word (program pengolah kata) (butir 4), namun hanya $60 \%$ guru yang mengaku memiliki alamat email pribadi (butir
5). Sebanyak $80 \%$ guru dapat mengirim dan membaca email (butir 6) dan 60\% guru menyatakan mampu mengirim dan menerima attachment/lampiran lewat email (butir7). Pada pernyataan butir 8 , tampak $80 \%$ guru mampu melakukan browsing Internet. Pada butir ke 9, jumlah guru yang mengaku mampu mencari informasi di internet lebih banyak yaitu $100 \%$. Guru yang mampu bernavigasi di suatu website untuk mendapatkan informasi yang diinginkan ada sebanyak $80 \%$ (butir 10). Jumlah guru yang menyatakan mampu mendownloaddokumen dari internet sebanyak $80 \%$ (butir 11). Meskipun persentase guru yang mampu melakukan pencarian informasi di internet cukup, namun pada pernyataan butir 12 , ternyata hanya $40 \%$ guru yang mampu melakukan bookmark websites yang mereka anggap bermanfaat. Jumlah guru yang menggunakan internet sebagai media komunikasi hanya sebagian kecil saja, yaitu sebanyak $20 \%$, yang mengaku familiar dengan milis (mailing list) dan kelompok diskusi online (butir ke 13), serta pernah berpartisipasi dalam online chat (butir 14).

Jumlah guru yang memanfaatkan TIK untuk mengelola pembelajaran terlihat dari data berikut. Dari butir 15, hanya sebagian kecil, yaitu 40\% guru yang mengaku menggunakan program Excel(program pengolah angka) untuk mengolah hasil penilaian terhadap siswa mereka. Untuk pembelajaran di kelas, hanya 20\% guru yang selalu mempergunakan program PowerPoint (program persentasi) untuk menyampaikan pembelajaran di kelasnya (butir 16). Pada pernyataan butir 17 , ternyata $100 \%$ guru mengaku memperkaya bahan pembelajarannya dengan materi yang relevan yang didapat dari akses di internet. Dalam pembelajaran di kelas jumlah guru yang sudah mengintegrasikan pembelajaran dengan TIK juga persentasenya masih sedikit terlihat dari data berikut. Pada pernyataan butir 18 , ternyata hanya $60 \%$ guru yang memastikan siswanya memanfaatkan program Word dalam melakukan tugas untuk mata pelajaran yang diampu mereka. Pada pernyataan butir 19 dan butir 20, terbukti $0 \%$ guru, yang memastikan siswanya memanfaatkan program Exceldan program PowerPointdalam melakukan tugas untuk mata pelajaran mereka.

Dalam pemanfaatan internet sebagai sumber belajar banyak guru yang sudah memastikan siswa untuk memanfaatkan internet. Pada pernyataan butir 21, sebanyak $60 \%$ guru mengaku memastikan siswanya mencari materi dengan memanfaatkan internet untuk melakukan tugas mata pelajaran mereka. Sebanyak 20\% guru memastikan siswanya memanfaatkan peralatan audio-video untuk melakukan tugas mata pelajaran mereka (butir 22). Pada pernyataan butir 23, semua guru (0\%) mengaku siswa mereka belum mampu membuat presentasi tugas dalam bentuk multi media.

Secara keseluruhan profil kompetensi guru dalam 
pemanfaatan TIK sebagai media pembelajaran sebanyak $54 \%$. Hal ini berarti bahwa sebagian besar guru masih belum memanfaatkan TIK sebagai media pembelajaran di kelas. Adapun data hasil olahan yang diisi/dijawab oleh responden. Kepala Sekolah dalam merespon kebijakan pemanfaatan TIK di sekolahnya adalah sebagai berikut.

Tabel 2. Kelbijakan Kepala Sekolah dalam Pemanfaatan TIK di Sekolahnya

\begin{tabular}{|c|c|c|c|c|c|c|c|c|}
\hline \multirow[b]{2}{*}{$\begin{array}{c}\text { Butil } \\
\text { Pertanyaan }\end{array}$} & \multicolumn{5}{|c|}{ Nama Kepala Sekolah } & \multirow[b]{2}{*}{ jumlah } & \multirow[b]{2}{*}{$\begin{array}{l}\text { Rata- } \\
\text { Rata }\end{array}$} & \multirow[b]{2}{*}{$\begin{array}{r}\text { Present- } \\
\text { tase }\end{array}$} \\
\hline & A & B & C & D & E & & & \\
\hline 1 & 1 & 1 & 0 & 1 & 1 & 4 & 0.8 & $80 \%$ \\
\hline 2 & 1 & 0 & 1 & 0 & 0 & 2 & 0.4 & $40 \%$ \\
\hline 3 & 1 & 0 & 1 & 0 & 0 & 2 & 0.4 & $40 \%$ \\
\hline 4 & 1 & 1 & 1 & 1 & 1 & 5 & 1 & $100 \%$ \\
\hline 5 & 1 & 1 & 1 & 1 & 1 & 5 & 1 & $100 \%$ \\
\hline 6 & 1 & 1 & 1 & 0 & 0 & 3 & 0.6 & $60 \%$ \\
\hline 7 & 1 & 0 & 1 & 0 & 0 & 2 & 0.4 & $40 \%$ \\
\hline 8 & 1 & 1 & 0 & 0 & 0 & 2 & 0.4 & $40 \%$ \\
\hline 9 & 1 & 0 & 0 & 0 & 0 & 1 & 0.2 & $20 \%$ \\
\hline 10 & 1 & 1 & 0 & 1 & 0 & 3 & 0.6 & $60 \%$ \\
\hline \multicolumn{8}{|c|}{ Total } & $58 \%$ \\
\hline
\end{tabular}

Sumber : Hasil penelitian, 2012

Berdasarkan data pada Tabel 2, yang diisi oleh 5 orang kepala sekolah, menghasilkan data sebagai berikut: sebanyak $80 \%$ kepala sekolah dapat mengakses komputer yang dapat diandalkan (pada butir no.1). Pada butir 2 dan butir 3, sebanyak $40 \%$ kepala sekolah selalu memerintahkan guru-gurunya agar menggunakan program Excel untuk mengolah hasil penilaian siswa dan memastikan guru-gurunya telah menggunakan program PowerPoint untuk menyampaikan pembelajaran di kelas.

Sebanyak $100 \%$ kepala sekolah sudah memerintahkan guru-gurunya untuk memperkaya bahan pembelajaran dengan materi yang relevan yang dapat dari akses di internet (butir 4) dan selalu memastikan guru-guru untuk memanfaatkan program Word dalam melakukan tugas untuk mata pelajarannya (Butir 5). Adapun pada butir 6, sebanyak $60 \%$ kepala sekolah selalu memastikan guruguru memanfaatkan Program Excel dalam melakukan tugas untuk mata pelajarannya, sedangkan hanya terdapat $40 \%$ kepala sekolah yang selalu memastikan guru-guru memanfaatkan program Powerpoint dalam melakukan tugas untuk mata pelajarannya (pada butir 7).

Sebanyak 40\% kepala sekolah juga yang selalu memastikan guru-guru untuk mencari materi dengan memanfaatkan internet untuk melakukan tugas mata pelajarannya (pada butir 8), namun hanya $20 \%$ kepala sekolah yang memastikan guru-guru untuk memanfaatkan peralatan audio-video untuk melakukan tugas mata pelajaran (pada butir 9) dan sebanyak 60\% kepala sekolah sudah mampu membuat presentasi tugas dalam bentuk multi media, seperti laporan hasil penelitian, ketrampilan dan sebagainya(butir 10).

Secara keseluruhan kebijakan kepala sekolah dalam pemanfaatan TIK di sekolah sebanyak 58\%. Hal ini berarti bahwa sebagian besar kepala sekolah dalam kebijakannya berhasil mendorong pemanfaatan TIK sebagai media pembelajaran bagi sekolahnya.

Hasil wawancara dengan guru-gurudiperoleh informasi bahwa semua guru yang diwawancarai mengaku bahwa mereka belum pernah mendapatkan pelatihan tentang cara mengintegrasikan Teknologi Informasi dan Komunikasi sebagai media pembelajaran mereka belum banyak memanfaatkan TIK dalam pembelajaran karena sarana yang ada dan kemampuan mereka belum memadai untuk melakukan hal tersebut. Kesulitan yang mereka hadapi untuk dapat mengintegrasikan TIK dalam pembelajaran antara lain fasilitas komputer yang belum lengkap, belum adanya pelatihan mengenai pengintegrasian TIK dalam pembelajaran, banyak guru yang belum memiliki komputer, dan sulit mencari orang tempat bertanya.

Berdasarkan hal tersebut di atas bahwa ternyata guru-guru di Kabupaten Sorong belum sepenuhnya optimal dalam memanfaatkan Teknologi Informasi dan Komunikasi (TIK) dalam proses pembelajaran. Guna menyiapkan dan melaksanakan pembelajaran yang mengintegrasikan TIK di kelas, maka guru sebaiknya melakukan langkah berikut: memiliki komputer, mengintegrasikan TIK dengan KBM, menyiapkan materi dengan mencari di internet, membuat media seperti PowerPoint, dan menyiapkan alat TIK. Tentunya untuk mempersiapkan hal tersebut, diperlukan pelatihan yang kontinu untuk pengintegrasian TIK dalam pembelajaran di sekolah yang harus diikuti semua guru dengan mendatangkan pakar/instruktur yang kompeten, melengkapi fasilitas yang diperlukan untuk menjamin guru dapat melakukan kegiatan KBM yang mengintegrasikan TIK. Selanjutnya guru difasilitasi untuk mempresentasikan hasil mereka pada seminar-seminar yang relevan.

\section{SIMPULAN}

Berdasarkan hasil penelitian di atas, maka dapat ditarik kesimpulan sebagai beriku:

1. Sebagian besar guru ( $54 \%$ ) masih belum memanfaatkan TIK sebagai media pembelajaran di kelas.

2. Sebesar $58 \%$ kepala sekolah dalam kebijakannya berhasil mendorong pemanfaatan TIK di sekolahnya.

3. Faktor penyebab belum maksimalnya penggunaan media TIK dalam pembelajaran adalah kurangnya pelatihan dan juga minimnya ketersediaan sarana dan 
prasarana media pembelajaran khususnya TIK di setiap sekolah.

Adapun saran dalam penelitian ini sebagai berikut:

1. Agar guru-guru lebih mengoptimalkan dalam pemanfaatan TIK khususnya untuk mengemas bahan ajar di sekolahnya serta meningkatkan pengetahuan agar dapat mewujudkan self running creation, sehingga siswa akan lebih mudah dalam menyerap hasil pembelajaran.

2. Pihak pengambil kebijakan hendaknya harus merata dalam memberikan tugas kepada guru terutama dalam mengikuti pelatihan-pelatihan tentang penggunaan media pembelajaran khususnya media Teknologi Informasi dan Komunikasi.

3. Pihak pemerintah daerah, provinsi maupun pusat, hendaknya memfasilitasi sarana media pembelajaran maupun dalam bentuk pelatihan- pelatihan yang bersifat kontinu.

\section{DAFTAR PUSTAKA}

Alma, Buchori at al. 2009. Guru Profesional (Menguasai Metode dan Terampil Mengajar). Cet. Ke-2. Bandung: Penerbit Alfabeta

Anggoro, Toha.2007. Metode Penelitian. Jakarta: Universitas Terbuka

Arikunto, Suharsimi, 2006. Prosedur Penelitian Suatu Pendekatan Praktik, Jakarta: Rineka Cipta. Direktorat Pembinaan SMA (2010). Juknis Pemanfaatan TIK Dalam Penilaian di SMA. Jakarta: Direktorat Pembinaan SMA

Kunandar. 2008. Guru Profesional Implmentasi Kurikulum Tingkat Satuan Pendidikan (KTSP) dan Sukses dalam Sertifikasi Guru. Edisi I. Jakarta: PT. RajaGrafindo Persada.

Partino, H.R. 2007. Metodologi Penelitian Kuantitatif. Jogyakarta: Pustaka Mahasiswa

Peraturan Menteri Pendidikan Nasional (Permendiknas) Nomor 16 Tahun 2007 tentang Standar Kualifikasi Akademik dan kompetensi Guru Peraturan Menteri Pendidikan Nasional (Permendiknas) Nomor 2 Tahun 2010 tentang Rencana Strategis Kementerian Pendidikan Nasional 2010-2014. 